\title{
How to Study Well-Being: A Proposal for the Integration of Philosophy With Science
}

202I, Vol. 25(2) I52-162

(C) 2021 The Author(s)

\section{(c) (i)}

Article reuse guidelines:

sagepub.com/journals-permissions DOI: |0.| | 77// 08926802| | 002443 journals.sagepub.com/home/rgp @SAGE

\author{
Michael Prinzing' (D)
}

\begin{abstract}
There are presently two approaches to the study of well-being. Philosophers typically focus on normative theorizing, attempting to identify the things that are ultimately good for a person, while largely ignoring empirical research. The idea is that empirical attention cannot be directed to the right place without a rigorous theory. Meanwhile, social scientists typically focus on empirical research, attempting to identify the causes and consequences of well-being, while largely ignoring normative theorizing. The idea is that conceptual and theoretical clarity will come with time and more data. This article argues that neither is a good approach to the study of well-being. The traditional philosophical approach underappreciates the vital importance of empirical investigation, whereas the atheoretical empirical approach underappreciates the vital importance of normative theorizing. The proposed solution is to bring these methods together. Well-being research should be interdisciplinary. The article proposes a "conceptual engineering" approach as a novel alternative. This approach involves an iterative process of normative theorizing, empirical investigation, and conceptual revision, with the aim of articulating concepts and theories of well-being that optimally suit particular interests and purposes.
\end{abstract}

\section{Keywords}

interdisciplinary research, normative theory, positive psychology, welfare economics

Well-being - or welfare, flourishing, the state of doing or being well-is a central and important topic in social science as well as moral and political philosophy. When people make decisions for themselves, or offer advice to others, they often focus on how different options will affect the well-being of the relevant parties. Similarly, policymaking by governments and other bodies, such as health care providers, is often aimed at protecting or promoting well-being. Thus, advancing collective understanding of well-being and how it can be promoted is perhaps one of the most important things academics can do. Philosophers have been studying well-being for millennia (Fletcher, 2016, pt. 1). But, in the past few decades, there has been a surge of interest in the topic among scientists - particularly in social psychology, but also economics and other social sciences (Dalziel et al., 2018; Diener, 2009; Forgas \& Baumeister, 2018; McDaid \& Cooper, 2014; McGregor \& Pouw, 2017; Proctor, 2017). This scientific research is taken seriously by governments and other organizations (Diener, 2012), adding practical weight to the question of how the topic should be investigated. What, in other words, should well-being research look like?

There are presently two standard approaches. In philosophy, the study of well-being consists primarily in normative theorizing (Kagan, 2018, Chapter 1). Philosophers who study well-being seek to identify the things that are ultimately good for a person (Crisp, 2017). Typically, this involves proposing theories of well-being and then applying these theories to (real or hypothetical) examples, to test the implications. Theories found to have counterintuitive implications are then revised, and the process iterates. The idea behind this focus on conceptual and theoretical clarity is that empirical research, while useful for identifying the correlates, causes, and consequences of observable phenomena, cannot reveal which of these phenomena is wellbeing. Only a philosophical theory can do that. It is therefore impossible to know where to direct empirical attention prior to settling on such a theory. This approach is not unanimously accepted by philosophers (Bishop, 2015; Tiberius, 2013; see Fabian, 2020, for a discussion of Bishop's "inclusive approach"). But it is certainly the status quo (Feldman, 2010; Sumner, 1996).

'The University of North Carolina at Chapel Hill, Chapel Hill, NC, USA

\section{Corresponding Author:}

Michael Prinzing, The University of North Carolina at Chapel Hill, Caldwell Hall, Emerson Drive, Chapel Hill, NC 275I4, USA.

Email: prinzing@live.unc.edu 
In the social sciences, the study of well-being takes the opposite approach. A wide range of empirical methods are deployed, while, typically, little effort is directed toward theorizing about the nature of well-being. The idea behind this approach is that it is quite common for scientific research to begin with only a vague idea of what it is investigating (Bishop, 2015, p. 152; Firestein, 2012). For instance, physicists studied light for hundreds of years all the while debating whether it is made of particles or waves (Stark, 2020). Some very fruitful programs of research in psychology also began with little theoretical foundation. Terms like "intelligence" are notoriously difficult to define, and it would seem naïve to think one could identify the core dimensions of personality a priori. Hence, in developing IQ testing and models of personality, many researchers adopted a kind of "data-driven" approach-deferring theoretical questions until there was more empirical evidence (Bartholomew, 2004; McCrae \& John, 1992; Richardson, 2002). Similarly, the reasoning goes, scientists interested in well-being can move straight to empirical investigation and deal with theoretical questions later. This atheoretical approach is rarely stated explicitly by social scientists, but it is frequently assumed (Argyle, 2013; Diener, 2009, p. 13; Kesebir \& Diener, 2008, p. 119), and most clearly exemplified by positive psychology (Seligman \& Csikszentmihalyi, 2000; Snyder \& Lopez, 2002).

These two approaches produce a silo effect. Philosophers and scientists, for the most part, ignore each other's work. ${ }^{1}$ Many seem to think that, as Fred Feldman (2010), a philosopher, puts it, there are "two distinct projects that call for two distinct workforces" (p. 7). In fact, the reasoning behind each of these approaches can be seen as arguments for ignoring research in other disciplines. If all empirical findings are hostage to philosophical fortune, then there's no reason for philosophers to bother consulting those findings until their work is done. Thus, "the philosophical project has priority over the empirical project" (Feldman, 2010, p. 8). Meanwhile, if philosophical theories are unnecessary for scientific research, then there is no reason for scientists to familiarize themselves with the philosophy. Social scientists will therefore claim that their fields occupy "an important and privileged position when it comes to understanding the nature of human well-being" (Forgas \& Baumeister, 2018, p. 1). So long as the standard approaches to the study of well-being predominate, this isolationism is likely to persist. That would be unfortunate. Methods and research questions differ. But, ultimately, philosophers and scientists alike are interested in understanding what it is to live well, and how to help people do so. And there is much that they could learn from each other.

This article is a plea for all sides to work together. It argues that philosophical and empirical methods are each limited, but that their weaknesses are complementary. Hence, the way forward is to combine these different approaches. This article begins by discussing the problems with the extant approaches. It then explains how interdisciplinarity (research produced either by collaboration between disciplinary specialists, or by researchers who specialize in well-being rather than any particular discipline) addresses these problems. Finally, the article introduces a "conceptual engineering" approach as a model for future, interdisciplinary research. The conceptual engineering approach involves a back and forth between empirical investigation and normative theorizing. The goal is to design concepts of wellbeing that are both descriptive and normative, and to continually reengineer them based on ongoing empirical investigation and critical evaluation.

\section{Problems With the Philosophical Approach}

Philosophers have typically assumed that a theory of wellbeing consists in an analysis of the ordinary concept of well-being. As James Griffin (1988) put it, "the notion [philosophers] are after is the ordinary notion of "well-being" (p. 10). Thus, they have tended to consider "descriptive adequacy" the primary criterion for evaluating such theories. A theory "is descriptively adequate only if it is faithful to our ordinary concept" (Sumner, 1996, p. 20). In other words,

[T] he best theory about the nature of welfare is the one which is most faithful to our ordinary concept and our ordinary experience. That experience is given by what we think or feel or know about well-being . . . The data which a candidate theory must fit, therefore, consist of the prodigious variety of our preanalytic convictions. (Sumner, 1996, pp. 10-11)

A successful theory will systematize and make sense of these common-sense judgments about well-being. This is not to say that descriptive adequacy is the only criterion. For instance, Sumner (1996) mentions "normative adequacy" as another possibility. (By this, he means the suitability of the concept to play a particular role in theories of, for example, rationality or morality.) Yet faithfulness to the ordinary concept is typically given priority.

One problem with the traditional philosophical approach is its apparent lack of progress (Chalmers, 2015). Philosophers have been arguing over theories of well-being for about as long as philosophy has existed. Yet the standard views, arguments, and objections haven't changed much in the past two millennia (Prinzing, 2020a, n. 4). The most common theories of well-being in the contemporary philosophical literature - mental state, desire-satisfaction, and objectivist (Crisp, 2017) - have been around since ancient Greece. To the extent that there has been progress, it has come largely from refining and combining these ancient ideas. For instance, "hybrid" theories have recently become 
common (Woodard, 2015). It is unlikely that more armchair reflection will resolve these ancient disputes. If empirical research on well-being must wait for the resolution of such disputes, then it will likely never begin.

But, perhaps knowing more about human nature and its potential, or about the social worlds in which people find themselves, would facilitate progress. For example, according to the hedonistic theory of well-being, the only thing that is ultimately good for a person is pleasure. A classic objection to hedonism (or at least one version of hedonism) is that there is no unified state or property behind the many, diverse forms of pleasure (Parfit, 1986, p. 493; Sidgwick, 1874, p. 127). If true, this would mean that there is no single phenomenon for hedonists to identify as that which is good for a person. However, affective science seems to show that there is such a phenomenon (Barrett \& Russell, 1999; Berridge, 2003; Berridge \& Kringelbach, 2013a, 2013b). And at least one philosopher has cited this discovery as a rebuttal to this objection (Crisp, 2006, p. 111). In this way, empirical research has helped to advance an old philosophical debate. Of course, there's no guarantee that empirical data will resolve all or even most philosophical disagreements. In fact, it would be reasonable to think not. Nevertheless, given the stagnation of the traditional philosophical approach, there is ample justification for trying something new. Empirical insights can at the very least give theorists a clearer sense of what they are disagreeing about and why they disagree.

Why are these philosophical disputes so intractable? One likely answer is that the "prodigious variety of preanalytic convictions" that Sumner (1996) wanted to systematize is not consistent. Intuitive judgments about well-being may contradict each other, between and perhaps also within individuals. If so, any consistent theory of well-being will violate some intuitive or commonsensical judgments (Bishop, 2015, Chapter 2). Of course, to determine whether this is the case, it will be necessary to understand how ordinary people use the concept of well-being. This is exactly the kind of research question that "experimental philosophy" was developed to answer (Knobe \& Nichols, 2017). Experimental philosophy studies (typically) use vignettes to elicit lay judgments about philosophically important topics.

To illustrate, consider Robert Nozick's (1974) “experience machine" thought experiment. In this thought experiment, one is asked to imagine that there is a machine capable of simulating any experience one desires. While in the machine, a person can (artificially) experience passionate romance, writing a best-selling novel, achieving great political ambitions, anything at all. However, these simulations are private ones. There are no real people in the virtual world. Moreover, in reality, anyone plugged into the machine is sitting motionless and alone. The question is then: Would you plug yourself in? Would you prefer to live in the solipsistic virtual world, or live in the real world, even if it's less pleasant? Most people (about $80 \%$ ) prefer to stay in the real world (De Brigard, 2010; Hindriks \& Douven, 2018). This thought experiment was long considered by some philosophers to constitute a clear counterexample to mental state theories of well-being (Bramble, 2016). If people don't want to plug in, it must be that they think that there is more to a good life than experiencing certain mental states.

However, experimental philosophers have found that Nozick's original formulation of this thought experiment is subject to the status quo bias - that is, a seemingly irrational preference for one's present state (De Brigard, 2010; Kahneman et al., 1991; Weijers, 2014). When the thought experiment is modified to avoid the effect of the status quo bias, about half of people say that they would plug in, while half say that they would not (De Brigard, 2010; Weijers, 2013, 2014). Thus, when intuitions about the prospect of a pleasant virtual reality are "de-biased," they do not clearly speak against mental state theories.

This illustrates the importance of empirical research, even on the assumption that well-being research must begin with a clarification of the ordinary concept of well-being. Empirical evidence can help to support or refute the empirical premises that appear in arguments for different theories of well-being. Empirical evidence can also help theorists to sort through intuitions about what is good and bad for a person, shedding light on the ordinary concept of wellbeing. If the ordinary concept of well-being does turn out to be inconsistent or otherwise defective-or if there is no such thing as the ordinary concept - then faithfulness to the ordinary concept is a misguided standard for theories of well-being. Theories shouldn't seek to clarify ordinary thinking; they should seek to refine it.

However, it is plausible that theories of well-being should be doing this regardless. Prioritizing descriptive adequacy encourages theorists to make empirically uninformed evaluations. Even if one could articulate a single, coherent concept of well-being, its content will necessarily be constrained by one's present understanding of the way the world works. Hence, if there is such a thing as the ordinary concept of well-being, it is a reflection of the ordinary (i.e., pre-scientific, often parochial) understanding of human beings, their capacities and potential, and the innumerable ways in which a human life can go. This does not seem like something worthy of conservation. Instead, concepts of well-being ought to reflect the best available empirical evidence. Well-being judgments are normative judgments, and proper normative judgments require a thorough understanding of their objects. This implies that concepts of well-being ought to be continually updated. As scientific methods are some of the best tools for learning about the phenomena that well-being judgments are about, they should be employed in this process. 
To be clear, the claim is not that the ordinary concept of well-being should be disregarded. Ordinary concepts are an important starting point for theorizing. Completely disregarding commonsense could lead, not to an improved understanding of well-being, but to a complete change of subject. (I.e., one might continue to use the word "wellbeing" but be talking about something totally disconnected from what people ordinarily care about when using that word.) However, so long as the topic is preserved, theorists should seek to change - and improve - the way in which well-being is conceptualized.

There are two lessons to draw from a consideration of the traditional philosophical approach to the study of wellbeing. First, the descriptive adequacy criterion does not justify philosophers in ignoring empirical research. Second, descriptive adequacy should not be given such priority anyhow. Theories of well-being should seek to improve, update, and refine the ordinary concept, not preserve it as-is. Normative theories should be updated in the light of ongoing empirical discovery.

\section{Problems With the Social Scientific Approach}

Just as philosophical methods alone are inadequate, so too are empirical methods. Some have criticized scientific efforts to understand well-being on the grounds that researchers lack clear definitions and theories (Feldman, 2010). The science of well-being has been called "a giant hodgepodge . . . [with] no agreed upon definition" of its central topic (Bishop, 2015, p. 4). The scientists themselves sometimes acknowledge this (Dodge et al., 2012; Forgeard et al., 2011; Fowers, 2008; Kashdan et al., 2008; Robbins \& Friedman, 2017; Ryff \& Keyes, 1995; Waterman, 2008). But, as indicated above, a lack of conceptual or theoretical clarity is not necessarily a problem for a fledgling science. So long as the researchers are pointed in the right direction, conceptual and theoretical clarity can come with time and new data (Bishop, 2015, p. 152; Firestein, 2012).

The problem with this atheoretical approach is not that it presently lacks satisfactory definitions and theories. It is that whatever definitions or theories do emerge from this approach are unlikely to be "normatively adequate" (Tiberius, 2018) - that is, they will not show why well-being is good and why people should value it. Empirical methods can uncover relationships between phenomena like positive affect, life satisfaction, and income. But-unless paired with normative claims or assumptions - they cannot tell us what is ultimately valuable or worth pursuing. To assume otherwise is to commit the "naturalistic fallacy," sliding erroneously from descriptive claims to normative claims (Brinkmann, 2009; Frankena, 1939; McPherson, 2016; Wilson et al., 2003). As a person's well-being consists in those things that are ultimately good for them, a satisfactory theory of well-being must make both descriptive and normative claims (Prinzing, 2020b; Tiberius, 2013, 2015).

Unless supplemented with normative theory, empirical methods are unlikely to produce normatively adequate definitions or theories. For, unless given reason to do otherwise, scientists will use "the most scientifically useful concepts ... [i.e.,] those that can be measured and show, within a theoretical framework, interesting relationships to other variables" (Diener, 2009, p. 13). The most scientifically useful concepts might turn out to overlap perfectly with the most normatively significant concepts. But there is no reason to think that would be the case (Haybron, 2000, pp. 216-217).

The problem with the standard atheoretical approach, in other words, is that it presupposes that well-being is a natural kind, like water or gold (Bird \& Tobin, 2018). Yet wellbeing is (also) a normative kind (Tiberius, 2013). As philosopher Geoff Sayre-McCord (1997) wrote,

In contrast with natural kind terms, we don't, and don't believe we should, defer to scientists or scientific theory in determining the true nature of what we are referring to in using [normative] terms. Instead, we adjust our views of what is good, or right, just, or obligatory, as we change our [normative] theory. (p. 270)

To illustrate, consider how a natural kind, like water, is investigated. To figure out what water is, scientists would gather samples of water, start quantifying their properties, and attempt to discern what all the samples have in common and what differentiates them from non-water liquids. Eventually, with the right tools and techniques, they would discover the fundamental composition of the samples $\left(\mathrm{H}_{2} \mathrm{O}\right)$. When this is done, the question "What is water?" has been answered. Contrast this with the case of wellbeing. Suppose researchers took some "samples" of wellbeing (people widely regarded as living good lives). Suppose, moreover, that the most distinctive property possessed by all of these people was a very high level of life satisfaction. This would not definitively answer the question "What is well-being?" It would still be perfectly reasonable to wonder just how good life satisfaction really is, and whether there's more to a life well-lived than feelings of satisfaction. This is because empirical discoveries alone cannot settle the question of what well-being is because they can't settle normative questions (McPherson, 2016). (Some might claim that such empirical inscrutability makes normative claims suspect. But mathematical claims are equally immune to empirical support or refutation. No empirical discovery could by itself convince anyone that 2 $+2=5$. But it would be absurd to suggest that, for this reason, science must eschew mathematics. Hence, by parity of reasoning, empirical inscrutability should be no reason to dismiss normative claims.) 
Whereas the purpose of a natural kind concept (e.g., water) is to track some purely descriptive phenomenon while remaining flexible about its underlying essence, the purpose of a normative kind concept (e.g., well-being) is to track a normative phenomenon while remaining flexible about its descriptive character. This normative rigidity and descriptive flexibility can be seen throughout the philosophical literature. It is very common for philosophers to begin a discussion of well-being by claiming that, "whatever well-being turns out to be, it will be something with great personal and moral significance" (Campbell, 2016, p. 404; see also: Scanlon, 1998; Sumner, 1996, pp. 1-4; Tiberius, 2004, p. 308; Tiberius \& Plakias, 2010, p. 402). These philosophers are claiming that, whatever is true of it descriptively, we can be certain that well-being consists in those things that are ultimately good for a person.

The takeaway should be that investigating well-being requires normative theorizing as well as empirical investigation. A theory of well-being is more than just a description of the world. Thus, empirical methods - while extremely important - are insufficient. Rather than trying to keep scientific and philosophical methods separate, a better approach would be to break down disciplinary boundaries.

\section{The Need for an Interdisciplinary Approach}

It seems that neither of the standard approaches to studying well-being is sufficient by itself. The way to avoid the problems discussed above is to pair the methods of different disciplines together. A useful metaphor is that each discipline shines a light from one direction, casting a long shadow in the other. The way to see the object of shared interest in its entirety is by shining multiple lights simultaneously. Indeed, a wide range of disciplines can contribute to well-being research. For instance, literature can be an important source of insight. Skillful normative thinking plausibly requires that one have been exposed to a wide array of evaluative perspectives. Reading novels can enable one to get "inside the head" of diverse characters, allowing for insight into others' values (Black \& Barnes, 2015; Kidd \& Castano, 2013; Mar et al., 2006).

Above, I argued that empirical discoveries can help to advance philosophical debates. The social sciences can similarly benefit from philosophical work. One example is how Jeremy Bentham's writings provided the basis for Kahneman et al.'s (1997) work on "objective happiness." But perhaps the clearest way in which the science of wellbeing has profited from philosophical efforts is in the growing field of eudaimonic psychology (Haybron, 2016; Heintzelman, 2018; Tiberius, 2016; Vitterso, 2016). Recognizing that something was missing from positive psychology's focus on affect and life satisfaction in the study of human flourishing, a number of researchers began to incorporate Aristotelian insights. Carol Ryff and Burton Singer (1998), for instance, drew heavily from Aristotle in proposing, "following from [their] philosophical analysis, that the key goods in life ... are, primarily, having purpose in life and quality connections to others; and secondarily, possessing self-regard and mastery" (p. 3). SelfDetermination Theory, another influential theory in the psychology of well-being, also borrows heavily from Aristotelian ideas (Ryan \& Deci, 2000; Ryan et al., 2013). ${ }^{2}$

Thus, it seems clear that philosophers and scientists would benefit from greater familiarity with each other's work. Some researchers, on both sides, are already onboard with this (e.g., Waterman, 2013, pp. 3-4). The recent appearance of interdisciplinary handbooks on well-being (Vitterso, 2016; Waterman, 2013) is an encouraging sign. And Valerie Tiberius (2013) has advocated that philosophers adopt a methodology that "involves taking account of people's pre-existing commitments, and refining the ideals by paying attention both to norms for rational improvement (norms that are employed in philosophical reflection) and to empirical data" (p. 228).

While such trends are encouraging, I argue that they haven't gone far enough. Familiarity with relevant work in another field - while certainly a step in the right directionmisses out on the value of expertise. Typically, scientists are not trained in philosophical methods, and philosophers are not trained in scientific ones. Specialization has its uses. But to take advantage of an intellectual division of labor, the specialists need to work together to produce the final product. As one example of the advantages of collaboration, consider a paper by Corey Keyes and Julia Annas (2009). These authors were responding to the argument that philosophical ideas about eudaimonia have little value for the science of well-being because they are not empirically distinguishable from "hedonic" aspects of well-being (Kashdan et al., 2008). Keyes and Annas argued that a proper understanding of eudaimonia (provided by Annas, a philosopher) enables a reanalysis of existing data (conducted by Keyes, a sociologist and psychologist), which shows that hedonia and eudaimonia are empirically distinct after all.

The merits of specialization, however, recommend something more radical than interdisciplinary collaboration. Rather than specialize in a particular discipline, like economics, philosophy, or psychology, researchers might specialize in well-being itself. Doctoral students in these disciplines receive training that has little bearing on wellbeing research. Economists typically learn real analysis, philosophers study symbolic logic, and psychologists learn about visual perception processing. These may be important for those who seek to be well-rounded practitioners of these disciplines. But have little to do with well-being research. In contrast, an interdisciplinary well-being specialist could draw from the literatures and methods that bear on 
well-being, regardless of their disciplinary origins. Training such specialists, while surely challenging in many ways, would have great value. Besides being especially productive well-being researchers, such specialists could facilitate collaboration between disciplinary specialists. Often the first hurdle in interdisciplinary projects is simply getting experts from diverse fields to communicate successfully. Domain specialists of this sort could be valuable translators or "go-betweens."

Given well-entrenched disciplinary distinctions, such interdisciplinary specialists would face serious obstacles. In the foreseeable future, well-being researchers will likely need to officially reside in one discipline or another. But, with time, that may change. The field of cognitive science offers historical precedent (Thagard, 2013). This field grew out of the recognition that the practitioners of many extant disciplines - from psychology to computer science to philosophy - all had something to contribute to research on the mind (Miller, 2003). At first, "cognitive science" was simply a name for collaborative research between these disciplines. Yet, it is now a discipline in its own right. Many universities now have cognitive science departments (see https://cognitivesciencesociety.org/programs-in-cognitivesciences/). Perhaps someday there will also be departments of "well-being studies."

\section{The Conceptual Engineering Approach}

What should interdisciplinary well-being research look like? Consideration of the two standard approaches taught three lessons: (a) theorists should be open to conceptual change, (b) this conceptual change should be guided by empirical insights, and (c) serious normative theorizing is essential. I argue that these lessons speak in favor of a "conceptual engineering" approach to the study of well-being (Burgess et al., 2019; Cappelen, 2018).

In contrast to traditional conceptual analysis, conceptual engineering is not especially concerned with faithfulness to ordinary concepts. Conceptual engineers argue that concepts should be subjected to critical scrutiny, just like beliefs (Prinzing, 2018). Hence, the goal of conceptual engineering is not to preserve, but to improve, ordinary concepts. Just as a mechanical engineer designs mechanical systems to serve specific purposes, a conceptual engineer designs concepts to serve specific purposes. Sometimes those purposes are abstract and theoretical. For instance, some philosophers seek to design a concept of "truth" that can perform certain logical functions (Scharp, 2013; Scharp \& Shapiro, 2017). In other cases, the relevant purposes are practical ones. For instance, some philosophers seek to design concepts of race and gender that, if adopted, could help to combat racism and sexism (Brigandt \& Rosario, 2020; Haslanger, 2000). Similarly, Dan Haybron (2003, 2008, Chapter 3) has defended a "reconstructive analysis" of happiness, which he thinks contradicts some ordinary intuitive judgments, but also respects certain practical interests that he attributes to laypeople. Conceptual engineers can be found in psychology as well. For instance, Barbara Fredrickson (2013, 2016) has argued that people should "upgrade" their concept of love - expanding beyond ordinary notions of intimacy and romance and including their day-to-day interactions, even with strangers. Using this broader concept of love, she argues, can lead to improved social interactions.

Some people object that disregarding ordinary concepts means changing the subject, failing to address the topic that motivated academic inquiry (Kauppinen, 2007, p. 98; Strawson, 1963 , p. 505). Within the context of well-being research, Alexandrova $(2017$, p. 93$)$ has argued that "objective happiness" conceptions of well-being commit this error. A common response to this kind of objection is that, so long as newly engineered concepts serve the same aims, purposes, or "functions" as the original concepts, then there is no problematic discontinuity (Nado, 2021; Prinzing, 2018). The idea is that concepts are mental tools, instruments for thinking about the world. If a newly engineered tool can do the same jobs as an older tool-only betterthen swapping the old tool for the new one does not lead to problems.

I suggested above that the endless philosophical debates about well-being result from inconsistencies in intuitive or common-sense judgments about well-being. One way of putting that point would be to say that there may simply be no single, consistent concept shared by all competent users of "well-being" and related terms. Perhaps this is because there are multiple aims or purposes for which we use "wellbeing." Some philosophers have argued that this is indeed the case. For instance, Shelly Kagan (1994) once argued that how well a person is doing and how well their life is going for them are distinct questions. As people and lives are not the same kinds of things, the standards for evaluating how well each is doing may differ. If so, then perhaps theories of well-being should distinguish between what might be called "well-doing" (how well a person is doing) and "well-going" (how well their life is going for them) and indicate how these two dimensions of evaluation come together in holistic assessments of well-being. Thomas Scanlon (1998) has argued that the concept of well-being has multiple theoretical "roles" to play. "Well-being" is often thought to play an important role in self-interested, beneficent, and moral decision-making. However, he argues that no single concept can play all three of these roles. This suggests that three concepts may be required.

More recently, some philosophers (Alexandrova, 2017; Mitchell \& Alexandrova, 2020) have argued that the most useful theories of well-being are "mid-level" theories - that is, theories that apply to particular groups or in particular contexts, rather than everyone everywhere. If this pluralistic approach were adopted, clearly many concepts and 
Table I. Criteria for concepts of well-being.

\begin{tabular}{ll} 
Criterion & Explanation \\
\hline Normativity & $\begin{array}{r}\text { Well-being is a normative kind. Hence, concepts of well-being should be suitable for evaluating how well someone is } \\
\text { doing, or how well their life is going. }\end{array}$ \\
Measurability & $\begin{array}{r}\text { Measurement is a prerequisite for scientific research. But laypeople should also be capable of using the concept } \\
\text { to assess (at least approximately) their own lives. Otherwise, the concept will not be usable in their practical } \\
\text { deliberations. }\end{array}$ \\
Precision & $\begin{array}{l}\text { Precise concepts are regarded as more useful for scientific purposes (Carnap, 1950; Wakil, 2020). Thus, all else being } \\
\text { equal, well-being theorists should strive for greater precision. } \\
\text { Mutability }\end{array}$ \\
$\begin{array}{l}\text { Concepts of well-being should pick out something that can be changed by a person's choices and actions. Otherwise } \\
\text { the concept will not be usable in their practical deliberation. }\end{array}$
\end{tabular}

theories of well-being would be required. The conceptual engineering approach is particularly well suited to handle these possibilities. If there are a variety of interests and purposes to be served, then a variety of concepts and/or theories can be developed to suit them.

\section{Comparison With "Reforming Definitions"}

Some philosophers have offered (or at least recognized the possibility of) "reforming definitions" (Railton, 1986) or "revisionist conceptual analyses" (Campbell, 2016, p. 405; Sumner, 1996, p. 12) of well-being. These are definitions or analyses of well-being that knowingly deviate somewhat from "the ordinary concept." In this respect, a reforming definitions approach to investigating well-being is similar to the one advocated here. However, it differs in several significant ways.

First, the aim of a reforming definition is to cleave as closely as possible to ordinary intuitions, while recognizing that securing a perfect match is likely to be impossible (Brandt, 1979, p. 193; Railton, 1989). In contrast, as indicated above, the aim of the conceptual engineering approach advocated here is to produce definitions and theories of well-being that optimally suit specific interests and purposes. While this is likely to entail a certain degree of fit with ordinary intuitions, this is not the ultimate goal.

Second, the advocates of reforming definitions do not discuss conceptual change or evolution, whereas this would be central to the conceptual engineering approach. The aim of the conceptual engineering approach is to design concepts using the best available empirical evidence and normative theories. Because the best available evidence is always changing, these concepts and corresponding theories should evolve along with that evidence. Hence, the conceptual engineering approach would involve an ongoing cycle of normative theorizing, empirical investigation, and conceptual revision. While clear definitions and theories of "well-being" would be given, they would never be permanently settled.
As this suggests, a third difference from a reforming definitions approach has to do with the role of empirical investigation. Whereas reforming definitions have previously been offered "from the armchair" (using purely philosophical methods), as an interdisciplinary approach, the process of conceptual engineering envisioned here would give a central role to empirical investigation.

\section{Criteria for Concepts of Well-Being}

How should the concepts produced by the conceptual engineering approach be assessed? Several criteria suggest themselves (see Table 1).

First, given that well-being is a normative kind, concepts of well-being should be normative. That is, they should be suitable for evaluating how a person is doing and/or how well their life is going for them. A purely descriptive concept would not respect the normative character of the topic.

Some philosophers have argued that a satisfactory theory of well-being will give us guidance about how to measure it empirically (Alexandrova, 2017; Tiberius, 2014). Yet there are others who think that well-being cannot be measured, at least not with the kinds of tools available to science (Hausman, 2015). For conceptual engineers, however, the resolution of this issue is a matter of decision. That is, even if well-being is not measurable according to "the ordinary concept," a concept of well-being could be engineered such that it is measurable. Indeed, as precise concepts are generally regarded as more useful for scientific research (Carnap, 1950; Wakil, 2020), the concept should be made as precise and measurable as it feasibly can.

More practically, the concept of well-being plays an important regulatory role in certain kinds of deliberation. So long as they are not suffering from psychopathology, people reliably seek to promote their own well-being, and the well-being of those they love. Therefore, if they are to perform their jobs well, concept(s) of well-being should also be able to feature prominently in ordinary decision-making. This places a few constraints on the descriptive content of the concept. For one thing, well-being should be the sort of thing that ordinary 
people - not just scientists - could assess, even if only roughly or by proxy. If laypeople could not, under ordinary circumstances, give (at least rough) answers to questions like "How well am I doing now?" and "How would choosing option A or B affect my well-being?," then they would not be able to use the concept in decision-making.

For related reasons, the phenomena identified by the concept should come in degrees, and the amount of it that a person has should be susceptible to change over time as a result of their actions. If people had no power to influence their well-being by choosing and acting in certain ways, then well-being considerations would have no place in their deliberation. There are sure to be other desirable features of concepts of well-being. The best way to see what makes for a good concept of well-being is probably to start designing and deploying such concepts.

\section{Conclusion}

This article argued that there are two standard approaches to the study of well-being. Philosophers tend to focus on normative theorizing, largely ignoring empirical research. This is problematic, because empirical evidence is important for clarifying ordinary judgments about well-being and also for informing those judgments. Meanwhile, social scientists tend to focus on empirical research, largely ignoring normative theorizing. This is problematic, because studying well-being involves making normative claims or assumptions. The article then argued that neither approach is sufficient on its own and that well-being research should therefore be interdisciplinary-that is, involve collaboration between disciplinary specialists, or work by wellbeing specialists who span disciplinary boundaries. Finally, the article proposed a "conceptual engineering" model for such interdisciplinary research. This novel approach would involve an iterative process of empirical investigation, normative theorizing, and conceptual revision. Philosophers and scientists would collaboratively design concepts and theories of well-being that serve specific interests and purposes related to evaluating how well a person is doing or how well their life is going for them. Of course, many concepts could be used to do that. Which cognitive tools are best suited to the task remains to be seen.

\section{Acknowledgments}

Many thanks to Luc Bovens, Mark Fabian, Barbara Fredrickson, and Joseph Porter for their comments on earlier drafts. Thanks are also due to the journal's anonymous reviewers for their helpful comments and suggestions.

\section{Declaration of Conflicting Interests}

The author(s) declared no potential conflicts of interest with respect to the research, authorship, and/or publication of this article.

\section{Funding}

The author(s) received no financial support for the research, authorship, and/or publication of this article.

\section{ORCID iD}

Michael Prinzing (iD https://orcid.org/0000-0002-7879-7131

\section{Notes}

1. There are some exceptions (Alexandrova, 2017; Deci \& Ryan, 2008; Haybron, 2016; Ryff \& Keyes, 1995; Ryff \& Singer, 1998; Tiberius, 2016, 2018). However, they make up a small minority of the very large group of well-being researchers. At the time of writing, a Google Scholar search for the keyword "well-being" returns nearly 2.3 million articles published since 2010 .

2. Some argue that these psychologists have misinterpreted Aristotle (Vitterso, 2016). If so, this is further support for the claim that philosophers and scientists should be working together, to avoid such mistakes.

\section{References}

Alexandrova, A. (2017). A philosophy for the science of wellbeing. Oxford University Press.

Argyle, M. (2013). The psychology of happiness. Routledge.

Barrett, L. F., \& Russell, J. A. (1999). The structure of current affect: Controversies and emerging consensus. Current Directions in Psychological Science, 8(1), 10-14. https://doi. org/10.1111/1467-8721.00003

Bartholomew, D. J. (2004). Measuring intelligence: Facts and fallacies. Cambridge University Press. https://doi.org/10.1017/ CBO9780511490019

Berridge, K. C. (2003). Pleasures of the brain. Brain and Cognition, 52(1), 106-128. https://doi.org/10.1016/S02782626(03)00014-9

Berridge, K. C., \& Kringelbach, M. L. (2013a). Neuroscience of affect: Brain mechanisms of pleasure and displeasure. Current Opinion in Neurobiology, 23(3), 294-303. https:// doi.org/10.1016/j.conb.2013.01.017

Berridge, K. C., \& Kringelbach, M. L. (2013b). Towards a neuroscience of well-being: Implications of insights from pleasure research. In H. Brockmann \& J. Delhey (Eds.), Human happiness and the pursuit of maximization (pp. 81-100). Springer. https://doi.org/10.1007/978-94-007-6609-9_7

Bird, A., \& Tobin, E. (2018). Natural kinds. In E. N. Zalta (Ed.), The Stanford encyclopedia of philosophy. https://plato.stanford.edu/archives/spr2017/entries/natural-kinds/

Bishop, M. (2015). The good life: Unifying the philosophy and psychology of well-being. Oxford University Press.

Black, J. E., \& Barnes, J. L. (2015). The effects of reading material on social and non-social cognition. Poetics, 52, 32-43. https:// doi.org/10.1016/j.poetic.2015.07.001

Bramble, B. (2016). The experience machine. Philosophy Compass, 11(3), 136-145. https://doi.org/10.1111/phc3.12303

Brandt, R. (1979). A theory of the good and the right. Clarendon Press.

Brigandt, I., \& Rosario, E. (2020). Strategic conceptual engineering for epistemic and social aims. In A. Burgess, H. Cappelen, 
\& D. Plunkett (Eds.), Conceptual engineering and conceptual ethics (pp. 100-124). Oxford University Press.

Brinkmann, S. (2009). Facts, values, and the naturalistic fallacy in psychology. New Ideas in Psychology, 27(1), 1-17. https:// doi.org/10.1016/j.newideapsych.2007.10.001

Burgess, A., Cappelen, H., \& Plunkett, D. (Eds.). (2019). Conceptual engineering and conceptual ethics. Oxford University Press.

Campbell, S. (2016). The concept of well-being. In G. Fletcher (Ed.), The Routledge handbook of philosophy of well-being (pp. 402-413). Routledge.

Cappelen, H. (2018). Fixing language: An essay on conceptual engineering. Oxford University Press.

Carnap, R. (1950). Logical foundations of probability. The University of Chicago Press.

Chalmers, D. J. (2015). Why isn't there more progress in philosophy? Philosophy, 90(1), 3-31. https://doi.org/10.1017/ S0031819114000436

Crisp, R. (2006). Reasons and the good. Oxford University Press.

Crisp, R. (2017). Well-being. In E. Zalta (Ed.), The Stanford encyclopedia of philosophy. The Metaphysics Research Lab, Stanford University. https://plato.stanford.edu/entries/wellbeing/

Dalziel, P., Saunders, C., \& Saunders, J. (2018). Wellbeing economics: The capabilities approach to prosperity. Springer. https://doi.org/10.1007/978-3-319-93194-4

De Brigard, F. (2010). If you like it, does it matter if it's real? Philosophical Psychology, 23(1), 43-57. https://doi.org /10.1080/09515080903532290

Deci, E. L., \& Ryan, R. M. (2008). Hedonia, eudaimonia, and well-being: An introduction. Journal of Happiness Studies, 9(1), 1-11. https://doi.org/10.1007/s10902-006-9018-1

Diener, E. (Ed.). (2009). The science of well-being. Springer.

Diener, E. (2012). New findings and future directions for subjective well-being research. American Psychologist, 67(8), 590-597. https://doi.org/10.1037/a0029541

Dodge, R., Daly, A., Huyton, J., \& Sanders, L. (2012). The challenge of defining wellbeing. International Journal of Wellbeing, 2(3), 222-235. https://doi.org/10.5502/ijw.v2i3.4

Fabian, M. (2020). Improving interdisciplinary research in wellbeing-A review with further comments of Michael Bishop's the good life: Unifying the philosophy and psychology of well-being. Journal of Happiness Studies. Advance online publication. https://doi.org/10.1007/s10902-020-00333-6

Feldman, F. (2010). What is this thing called happiness? Oxford University Press.

Firestein, S. (2012). Ignorance: How it drives science. Oxford University Press.

Fletcher, G. (Ed.). (2016). The Routledge handbook of philosophy of well-being. Routledge.

Forgas, J., \& Baumeister, R. F. (Eds.). (2018). The social psychology of living well. Routledge.

Forgeard, M. J. C., Jayawickreme, E., Kern, M. L., \& Seligman, M. E. P. (2011). Doing the right thing: Measuring wellbeing for public policy. International Journal of Wellbeing, 1(1), 15. https://doi.org/10.5502/ijw.v1i1.15

Fowers, B. J. (2008). From continence to virtue: Recovering goodness, character unity, and character types for positive psychology. Theory \& Psychology, 18(5), 629-653. https:// doi.org/10.1177/0959354308093399

Frankena, W. K. (1939). The naturalistic fallacy. Mind, 48(192), 464-477.

Fredrickson, B. L. (2013). Love 2.0. Hudson Street Press.

Fredrickson, B. L. (2016). Love: Positivity resonance as a fresh, evidence-based perspective on an age-old topic. In L. F. Barrett, M. Lewis, \& J. M. Haviland-Jones (Eds.), Handbook of emotions (4th ed., pp. 847-858). Guilford Press.

Griffin, J. (1988). Well-being: Its meaning, measurement and moral importance. Oxford University Press.

Haslanger, S. (2000). Gender and race: (What) are they? (What) do we want them to be? Nô̂s, 34, 32-55.

Hausman, D. M. (2015). Valuing health: Well-being, freedom, and suffering. Oxford University Press.

Haybron, D. M. (2000). Two philosophical problems in the study of happiness. Journal of Happiness Studies, 1, 207-225.

Haybron, D. M. (2003). What do we want from a theory of happiness? Metaphilosophy, 34(3), 305-329.

Haybron, D. M. (2008). The pursuit of unhappiness: The elusive psychology of well-being. Oxford University Press.

Haybron, D. M. (2016). The philosophical basis of eudaimonic psychology. In J. Vittersø (Ed.), Handbook of eudaimonic well-being (pp. 27-53). Springer. https://doi.org/10.1007/9783-319-42445-3_2

Heintzelman, S. J. (2018). Eudaimonia in the contemporary science of subjective well-being: Psychological well-being, selfdetermination, and meaning in life. In E. Diener, S. Oishi, \& L. Tay (Eds.), Handbook of well-being. DEF Publishers. https://www.nobascholar.com/chapters/18/download.pdf

Hindriks, F., \& Douven, I. (2018). Nozick's experience machine: An empirical study. Philosophical Psychology, 31(2), 278298. https://doi.org/10.1080/09515089.2017.1406600

Kagan, S. (1994). Me and my life. Proceedings of the Aristotelian Society, New Series, 9, 309-324.

Kagan, S. (2018). Normative ethics. Routledge.

Kahneman, D., Knetsch, J. L., \& Thaler, R. H. (1991). Anomalies: The endowment effect, loss aversion, and status quo bias. Journal of Economic Perspectives, 5(1), 193-206. https://doi. org/10.1257/jep.5.1.193

Kahneman, D., Wakker, P. P., \& Sarin, R. (1997). Back to Bentham? Explorations of experienced utility. The Quarterly Journal of Economics, 112(2), 375-405.

Kashdan, T. B., Biswas-Diener, R., \& King, L. A. (2008). Reconsidering happiness: The costs of distinguishing between hedonics and eudaimonia. The Journal of Positive Psychology, 3(4), 219-233. https://doi.org/10.1080/17439 760802303044

Kauppinen, A. (2007). The rise and fall of experimental philosophy. Philosophical Explorations, 10(2), 95-118. https://doi. org/10.1080/13869790701305871

Kesebir, P., \& Diener, E. (2008). In pursuit of happiness: Empirical answers to philosophical questions. Perspectives on Psychological Science, 3(2), 117-125.

Keyes, C. L. M., \& Annas, J. (2009). Feeling good and functioning well: Distinctive concepts in ancient philosophy and contemporary science. The Journal of Positive Psychology, 4(3), 197-201. https://doi.org/10.1080/17439 760902844228 
Kidd, D. C., \& Castano, E. (2013). Reading literary fiction improves theory of mind. Science, 342(6156), 377-380. https://doi.org/10.1126/science.1239918

Knobe, J., \& Nichols, S. (2017). Experimental philosophy. In E. N. Zalta (Ed.), The Stanford encyclopedia of philosophy. Metaphysics Research Lab, Stanford University. https:// plato.stanford.edu/archives/win2017/entries/experimentalphilosophy/

Mar, R. A., Oatley, K., Hirsh, J., dela Paz, J., \& Peterson, J. B. (2006). Bookworms versus nerds: Exposure to fiction versus non-fiction, divergent associations with social ability, and the simulation of fictional social worlds. Journal of Research in Personality, 40(5), 694-712. https://doi.org/10.1016/j. jrp.2005.08.002

McCrae, R. R., \& John, O. P. (1992). An introduction to the fivefactor model and its applications. Journal of Personality, 60(2), 175-215. https://doi.org/10.1111/j.1467-6494.1992. tb00970.x

McDaid, D., \& Cooper, C. (2014). Wellbeing: A complete reference guide, economics of wellbeing. John Wiley.

McGregor, J. A., \& Pouw, N. (2017). Towards an economics of well-being. Cambridge Journal of Economics, 41, 11231142. https://doi.org/10.1093/cje/bew044

McPherson, T. (2016). Open question argument. In Routledge encyclopedia of philosophy (1st ed.). Routledge. https://doi. org/10.4324/9780415249126-L146-1

Miller, G. A. (2003). The cognitive revolution: A historical perspective. Trends in Cognitive Sciences, 7(3), 141-144. https:// doi.org/10.1016/S1364-6613(03)00029-9

Mitchell, P., \& Alexandrova, A. (2020). Well-being and pluralism. Journal of Happiness Studies. Advance online publication. https://doi.org/10.1007/s10902-020-00323-8

Nado, J. (2021). Conceptual engineering via experimental philosophy. Inquiry, 64, 76-96. https://doi.org/10.1080/00201 74X.2019.1667870

Nozick, R. (1974). Anarchy, state, and utopia. Basic Books.

Parfit, D. (1986). Reasons and persons. Oxford University Press. https://doi.org/10.1093/019824908X.001.0001

Prinzing, M. M. (2018). The revisionist's rubric: Conceptual engineering and the discontinuity objection. Inquiry, 61(8), 854-880. https://doi.org/10.1080/0020174X.2017.1385522

Prinzing, M. M. (2020a). Explanatory perfectionism: A fresh take on an ancient theory. Analysis, 80, 704-712. https://doi. org/10.1093/analys/anaa021

Prinzing, M. M. (2020b). Positive psychology is value-ladenIt's time to embrace it. The Journal of Positive Psychology. Advance online publication. https://doi.org/10.1080/1743976 0.2020 .1716049

Proctor, C. (Ed.). (2017). Positive psychology interventions in practice. Springer.

Railton, P. (1986). Facts and values. Philosophical Topics, 14(2), $5-31$.

Railton, P. (1989). Naturalism and prescriptivity. Social Philosophy and Policy, 7(1), 151-174. https://doi.org/10.1017/S02650 52500001060

Richardson, K. (2002). What IQ tests test. Theory \& Psychology, 12(3), 283-314. https://doi.org/10.1177/095935430201200 3012
Robbins, B. D., \& Friedman, H. L. (2017). The unavoidable role of values in positive psychology. In N. J. L. Brown, T. Lomas, \& F. J. Eiroa-Orosa (Eds.), The Routledge international handbook of critical positive psychology (pp. 15-25). Routledge.

Ryan, R. M., Curren, R. R., \& Deci, E. L. (2013). What humans need: Flourishing in Aristotelian philosophy and self-determination theory. In A. S. Waterman (Ed.), The best within us: Positive psychology perspectives on eudaimonia (pp. 57-75). American Psychological Association.

Ryan, R. M., \& Deci, E. L. (2000). Self-determination theory and the facilitation of intrinsic motivation, social development, and well-being. American Psychologist, 55(1), 68-78.

Ryff, C. D., \& Keyes, C. L. M. (1995). The structure of psychological well-being revisited. Journal of Personality and Social Psychology, 69(4), 719-727.

Ryff, C. D., \& Singer, B. (1998). The contours of positive human health. Psychological Inquiry, 9(1), 1-28. https://doi. org/10.1207/s15327965pli0901_1

Sayre-McCord, G. (1997). "Good" on twin earth. Philosophical Issues, 8, 267-292. https://doi.org/10.2307/1523011

Scanlon, T. (1998). What we owe to each other. Harvard University Press.

Scharp, K. (2013). Replacing truth. Oxford University Press.

Scharp, K., \& Shapiro, S. (2017). Revising inconsistent concepts. In B. Armour-Garb (Ed.), Reflections on the liar (pp. 257-280). Oxford University Press.

Seligman, M. E. P., \& Csikszentmihalyi, M. (2000). Positive psychology: An introduction. American Psychologist, 55(1), 5-14. https://doi.org/10.1037//0003-066X.55.1.5

Sidgwick, H. (1874). The methods of ethics. Hackett Publishing.

Snyder, C. R., \& Lopez, S. J. (Eds.). (2002). Handbook of positive psychology. Oxford University Press.

Stark, G. (2020). Light. In Encyclopedia Britannica. https://www. britannica.com/science/light

Strawson, P. F. (1963). Carnap's views on constructed systems versus natural languages in analytic philosophy. In P. A. Schilpp (Ed.), The philosophy of Rudolf Carnap (pp. 503-518). Open Court.

Sumner, L. W. (1996). Welfare, happiness, and ethics. Oxford University Press.

Thagard, P. (2013). Cognitive science. In Encyclopedia Britannica. https://www.britannica.com/science/cognitive-science

Tiberius, V. (2004). Cultural differences and philosophical accounts of well-being. Journal of Happiness Studies, 5(3), 293-314.

Tiberius, V. (2013). Well-being, wisdom, and thick theorizing: On the division of labor between moral philosophy and positive psychology. In S. Kirchin (Ed.), Thick concepts (pp. 217-233). Oxford University Press.

Tiberius, V. (2014). Beyond the experience machine: How to build a theory of well-being. In M. Haug (Ed.), Philosophical methodology: The armchair or the laboratory (pp. 398-415). Routledge.

Tiberius, V. (2015). Prudential value. In I. Hirose \& J. Olson (Eds.), The Oxford handbook of value theory (pp. 158-171). Oxford University Press.

Tiberius, V. (2016). The future of eudaimonic well-being: Subjectivism, objectivism and the lump under the carpet. 
In J. Vittersø (Ed.), Handbook of eudaimonic well-being (pp. 565-569). Springer. https://doi.org/10.1007/978-3-31942445-3_38

Tiberius, V. (2018). Well-being as value fulfillment: How we can help each other to live well. Oxford University Press.

Tiberius, V., \& Plakias, A. (2010). Well-being. In J. M. Doris (Ed.), The moral psychology handbook (pp. 402-428). Oxford University Press. https://doi.org/10.1093/acprof:oso /9780199582143.001.0001

Vitterso, J. (2016). Handbook of eudaimonic well-being. Springer.

Wakil, S. (2020). Objectivity and orgasm: The perils of imprecise definitions. Synthese. Advance online publication. https://doi. org/10.1007/s11229-020-02886-8

Waterman, A. S. (2008). Reconsidering happiness: A eudaimonist's perspective. The Journal of Positive Psychology, 3(4), 234-252. https://doi.org/10.1080/17439760802303002
Waterman, A. S. (Ed.). (2013). The best within us: Positive psychology perspectives on eudaimonia. American Psychological Association.

Weijers, D. (2013). Intuitive biases in judgments about thought experiments: The experience machine revisited. Philosophical Writings, 50(51), 1-18.

Weijers, D. (2014). Nozick's experience machine is dead, long live the experience machine!. Philosophical Psychology, 27(4), 513-535. https://doi.org/10.1080/09515089.2012.757889

Wilson, D. S., Dietrich, E., \& Clark, A. B. (2003). On the inappropriate use of the naturalistic fallacy in evolutionary psychology. Biology \& Philosophy, 18(5), 669-681. https://doi. org/10.1023/A:1026380825208

Woodard, C. (2015). Hybrid theories. In G. Fletcher (Ed.), The Routledge handbook of philosophy of well-being (pp. 161-174). Routledge. 